\title{
Kwalifikowanie spawaczy stali wg PN-EN 287-1:2011 i norm międzynarodowych
}

\section{Steel welders qualification requirements acc. to PN-EN 287-1:2011 and international standards}

\section{Streszczenie}

W artykule przedstawiono aktualne wymagania przy egzaminowaniu spawaczy wykonujących konstrukcje stalowe na podstawie wytycznych europejskiej normy PN-EN 287-1:2011. Omówiono też kolejną wersję normy międzynarodowej ISO/DIS 9606-1:2010, mającej wkrótce zastąpić normę PN-EN 287-1.

\section{Wstęp}

Nadawanie spawaczom uprawnień następuje po sprawdzeniu ich umiejętności i wiedzy, zgodnie z: PN-EN 287-1 - Egzamin kwalifikacyjny spawaczy. Spawanie. Część 1. Stale i normy serii PN-EN ISO 9606 - Egzaminowanie spawaczy. Spawanie m.in:

- PN-EN ISO 9606-2 Egzamin kwalifikacyjny spawaczy. Spawanie. Część 2 Aluminium i stopy aluminium,

- PN-EN ISO 9606-3 Egzamin kwalifikacyjny spawaczy. Spawanie. Część 3 Miedź i stopy miedzi,

- PN-EN ISO 9606-4 Egzamin kwalifikacyjny spawaczy. Spawanie. Część 4 Nikiel i stopy niklu,

- PN-EN ISO 9606-5 Egzamin kwalifikacyjny spawaczy. Spawanie. Część 5 Tytan i stopy tytanu, cyrkon i stopy cyrkonu.

Europejska norma EN 287-1, dotycząca egzaminowania spawaczy stali, ma już ponad 20 lat. Ustanowiona została 21 lutego 1992 r., a następnie przyjęta Uchwałą z 11 sierpnia 1998 r. przez Polski Komitet Normalizacyjny, i weszła do praktyki spawalniczej 1 stycznia 2000 r. [1].

Dr inż. Ryszard Pakos - Zachodniopomorski Uniwersytet Technologiczny w Szczecinie.
W ostatnich latach w Komitetach Technicznych Międzynarodowej Organizacji Normalizacyjnej (ISO), jak również w Europejskim Komitecie Normalizacyjnym (CEN), podjęto prace zmierzające do wprowadzenia zmian do norm na egzaminowanie spawaczy stali.

Członkowie Komitetu Technicznego Europejskiego Komitetu Normalizacyjnego (CEN) mając na uwadze ujednolicenie przepisów dotyczących kwalifikowania spawaczy nie tylko w Unii Europejskiej, szukali kompromisu wzorując się na projekcie międzynarodowej normy ISO 9606-1. W ostatnich latach do norm ISO 9606-1 i EN 287-1 wprowadzono istotne zmiany. Członkowie Komitetów Technicznych ISO, jak również CEN, prowadzili intensywne działania nad opracowaniem wspólnej wersji normy na egzaminowanie spawaczy stali, z jednakowym numerem 9606-1. W 2002 r. opublikowano projekty końcowe obydwóch norm, jednak ze względu na odmienne stanowisko Stanów Zjednoczonych w ISO nie doszło do ostatecznego ustanowienia wspólnej normy. Od 2 stycznia 2004 r. zobowiązano wszystkie kraje członkowskie CEN do wprowadzenia w życie znowelizowanej normy europejskiej EN 287-1: 2004. W Polsce jej odpowiednikiem była norma PN-EN 287-1:2005 (U). 16 lutego 2007 została zatwierdzona przez Prezesa PKN krajowa norma PN-EN 287-1:2007, w której uwzględniono poprawkę do normy AC:2004 oraz zmianę A2:2006. 


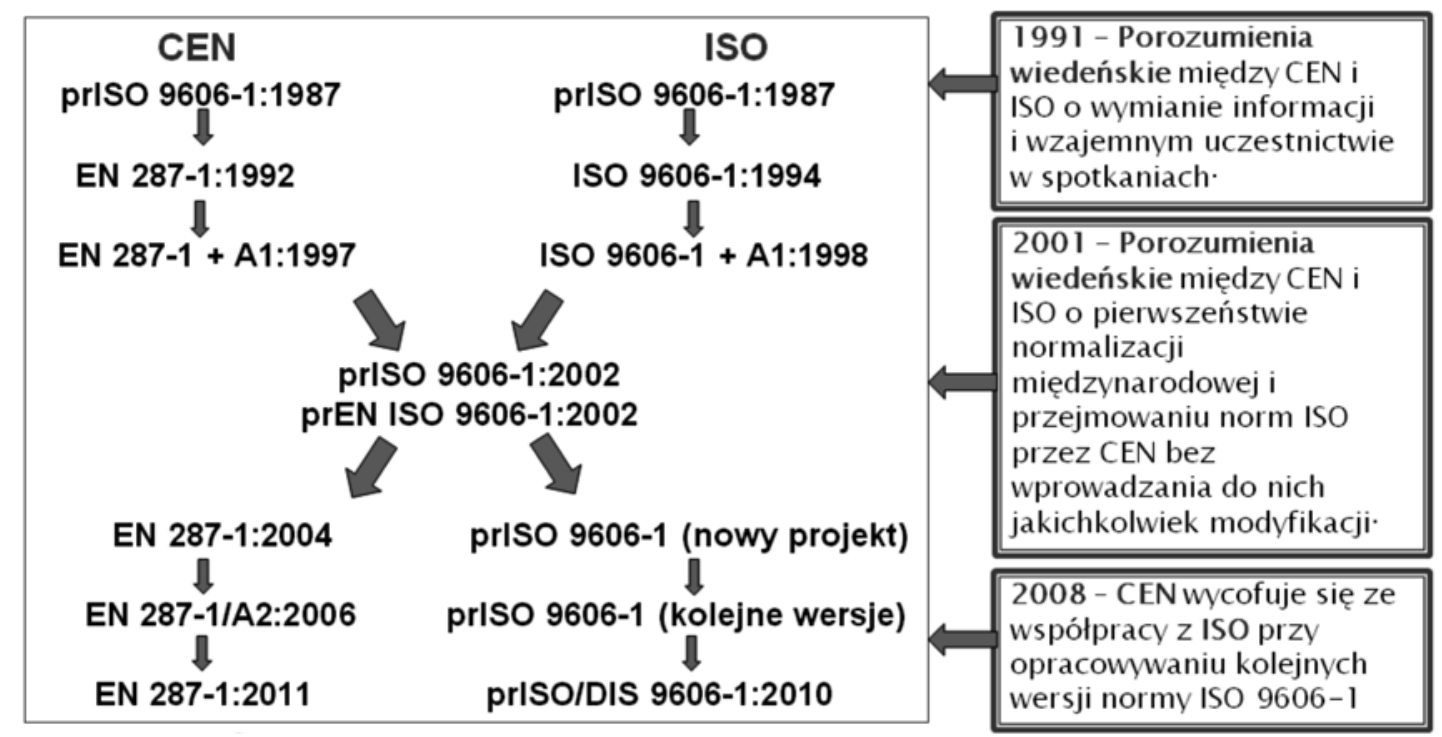

Rys. 1. Przebieg prac CEN i ISO nad wspólną normą [1]

Fig. 1. The course of the work of CEN and ISO on a common standard [1]

Od 2 grudnia 2011 r. zatwierdzono kolejna wersję normy, która zastępuje PN-EN 287-1:2011 i jest zharmonizowana z dyrektywą 97/23/ECl2009/105/ EC. Aktualna norma (przedstawiona na 40 stronach) podaje zestaw warunków technicznych egzaminu spawacza, umożliwiających akceptację jego umiejętności niezależnie od rodzaju wyrobu, lokalizacji i egzaminatora lub jednostki egzaminującej. Opisuje warunki odnoszące się do metod spawania uznanych za procesy ręczne i częściowo zmechanizowane.

W 2010 r. opublikowano również kolejną wersję projektu międzynarodowej normy ISO/DIS 9606$-1: 2010$, która jest zbliżona do normy europejskiej 287-1, jednak pewne istotne różnice między nimi nie doprowadziły do akceptacji przez Europejski Komitet Normalizacyjny (CEN). Znawcy tego problemu twierdzą, że w ciągu roku dojdzie do porozumienia i norma PN-EN 287 zostanie wycofana i zastapiona normą PN-EN ISO 9606-1.

Historię międzynarodowej i europejskiej normy dotyczącej kwalifikowania spawaczy stali przedstawiono na rysunku 1.

\section{Wybrane zmiany w PN-EN 287-1:2011}

\section{Procesy spawania [3]}

111 ręczne spawanie łukowe;

114 spawanie łukowe samoosłonowym łukiem proszkowym;

121 spawanie łukiem krytym jednym drutem elektrodowym;

125 spawanie łukiem krytym drutem proszkowym;

131 spawanie elektrodą metalową w osłonie gazów obojętnych (spawanie metodą MIG);

135 spawanie elektrodą metalową w osłonie gazów aktywnych (spawanie metodą MAG);
136 spawanie łukowe w osłonie gazu aktywnego drutem proszkowym;

138 spawanie elektrodą topliwą w osłonie gazu aktywnego drutem proszkowym o rdzeniu metalicznym;

141 spawanie elektrodą wolframową w osłonie gazów obojętnych (spawanie metodą TIG);

142 spawanie elektrodą wolframową w osłonie gazu obojętnego bez dodatku spoiwa;

143 spawanie elektrodą wolframową w osłonie gazu obojętnego z dodatkiem drutu lub pręta proszkowego;

145 spawanie elektrodą wolframową w osłonie gazu obojętnego z udziałem gazów redukujących i dodatkiem litego drutu lub pręta;

15 spawanie plazmowe;

311 spawanie acetylenowo-tlenowe.

Zwykle na każdym egzaminie ocenia się tylko jeden proces spawania. Zmiana procesu spawania wymaga nowego egzaminu kwalifikacyjnego. Omawiana norma dopuszcza jednak pewne wyjątki:

- zmiany drutu litego S (proces 135) na drut M z rdzeniem metalicznym (proces 138) lub odwrotnie - nie wymagają nowego egzaminu;

- spawanie metodami 141, 143 lub 145 jest ważne dla procesów spawania 141, 142, 143 i 145;

- proces spawania 142 dotyczy tylko tej metody.

\section{Typ spoiny}

Wprowadzono nowe kryteria dotyczące egzaminowania i kwalifikowania złączy ze spoiną czołową i pachwinową:

- zdany egzamin na spoiny czołowe nie daje uprawnień na spoiny pachwinowe lub odwrotnie;

- jeśli spawacz zdał egzaminy spoinę czołową, może wykonać uzupełniające złącze egzaminacyjne 
Tablica I. Zakres oceny uprawnień spawacza dla pozycji spawania [3]

Table I. The range of qualifications for the welder in different position welding [3]

\begin{tabular}{|c|c|c|c|c|c|c|c|c|c|c|c|}
\hline \multirow{2}{*}{$\begin{array}{c}\text { Pozycja spawania } \\
\text { złącza próbnego }\end{array}$} & \multicolumn{11}{|c|}{ Zakres kwalifikacji a } \\
\hline & PA & $\mathrm{PB}^{\mathrm{b}}$ & $\mathrm{PC}$ & PD ${ }^{b}$ & PE & PF (blacha) & $\mathrm{PH}$ (rura) & PG (blacha) & PJ (rura) & H-L045 & J-L045 \\
\hline PA & $X$ & $x$ & - & - & - & - & - & - & - & - & - \\
\hline $\mathrm{PB}{ }^{\mathrm{b}}$ & $X$ & $x$ & - & - & - & - & - & - & - & - & - \\
\hline $\mathrm{PC}$ & $\mathrm{X}$ & $X$ & $X$ & - & - & - & - & - & - & - & - \\
\hline$P D^{b}$ & $X$ & $X$ & $X$ & $X$ & $\mathrm{X}$ & $X$ & - & - & - & - & - \\
\hline PE & $X$ & $x$ & $\mathrm{X}$ & $X$ & $\mathrm{X}$ & $X$ & $x$ & - & - & - & - \\
\hline PF (blacha) & $X$ & $x$ & - & - & - & $X$ & - & - & - & - & - \\
\hline $\mathrm{PH}^{\mathrm{c}}$ (rura) & $x$ & $x$ & - & $x$ & $x$ & $x$ & $x$ & - & - & - & - \\
\hline PG (blacha) & - & - & - & - & - & - & - & $X$ & - & - & - \\
\hline $\mathrm{PJ}^{\mathrm{c}}$ (rura) & $X$ & $x$ & - & $x$ & $X$ & - & - & $X$ & $X$ & - & - \\
\hline H-L045 & $X$ & $X$ & $X$ & $X$ & $X$ & $X$ & $x$ & - & - & $X$ & - \\
\hline J-L045 & $x$ & $x$ & $x$ & $x$ & $x$ & - & - & $x$ & $x$ & - & $x$ \\
\hline \multicolumn{12}{|c|}{$\begin{array}{l}\text { a Dodatkowo powinny być przestrzegane wymagania } 5.3 \text { i } 5.4 \text { (p. norma) } \\
\text { b Pozycje spawania PB i PD są stosowane tylko dla spoin pachwinowych (p. 5.4.b) i mogą służyć do kwalifikacji tylko w innych pozycjach } \\
\text { spawania (p. norma) } \\
\text { c Pozycja spawania PH na rurze obejmuje pozycje spawania PE, PF i PA. Pozycja spawania PJ na rurze obejmuje pozycje spawania PA, } \\
\text { PG i PE (p. norma) } \\
\text { Opis: X - wskazuje te pozycje, do spawania których spawacz jest uprawniony; - wskazuje te pozycje, do spawania których spawacz nie } \\
\text { jest uprawniony. }\end{array}$} \\
\hline
\end{tabular}

ze spoiną pachwinową. Grubość blach powinna wynosić min. $10 \mathrm{~mm}$, a spawanie powinno się wykonać jednym ściegiem w pozycji spawania PB. Uzupełniające złącze egzaminacyjne uprawnia do wykonywania wszystkich spoin pachwinowych w zakresie kwalifikowania spoiny czołowej.

\section{Pozycje spawania}

Zgodnie z nową wersją EN ISO 6947:2011 Spawanie i procesy pokrewne, wprowadzono dwa nowe oznaczenia dla pozycji spawania. tj.:

- pozycja PH - spawanie rury z dołu do góry (dotychczas pozycja PF);

- pozycja PJ - spawanie rury z góry na dół (dotychczas pozycja $P G$ ).

Wynikający stąd zakres kwalifikacji dla pozycji spawania przedstawiono $\mathrm{w}$ tablicy $\mathrm{I}$.

\section{Warunki spawania}

Egzamin kwalifikacyjny spawacza powinien być przeprowadzony wg pWPS lub WPS, przygotowanych zgodnie z EN ISO 15609-1 lub EN ISO 15609-2. Wymagana grubość spoiny pachwinowej złącza egzaminacyjnego musi być określona w pWPS lub WPS, stosowanej dla tego egzaminu.

Powinny być zastosowane następujące warunki spawania:

- czas spawania złącza egzaminacyjnego powinien odpowiadać czasowi spawania w typowych warunkach produkcyjnych;

- złącze egzaminacyjne powinno mieć co najmniej jedno przerwanie spawania i jedno ponowne rozpoczęcie w ściegu warstwy graniowej i warstwy licowej i powinno być zidentyfikowane w badanej długości złącza;

- spawacz powinien mieć możliwość usuwania drobnych niezgodności spawalniczych przez szlifowanie. Wyłączona(e) jest/są ściegi warstwy licowej. Można szlifować tylko początek i koniec. Powinien uzyskać zgodę egzaminatora lub jednostki egzaminującej.

- z każdej obróbki cieplnej, która jest wymagana w pWPS lub WPS, można zrezygnować na odpowiedzialność wytwórcy.

\section{Wymagania dotyczące złączy egzaminacyjnych}

Wymagania dotyczące akceptacji niezgodności spawalniczych wykrytych metodami badania według omówionej normy powinny, chyba że określono inaczej, być ocenione zgodnie z EN ISO 5817. Spawacz uzyskuje uprawnienia, jeśli niezgodności spawalnicze mieszczą się na poziomie jakości B według EN ISO 5817, z wyjątkiem następujących niezgodności spawalniczych: nadlewu spoiny (spoina czołowa), nadlewu spoiny (spoina pachwinowa), nadmiernej grubości spoiny pachwinowej, wycieku, niewłaściwego brzegu spoiny i podtopień, dla których należy zastosować poziom jakości $C$.

Z treści tego akapitu zostały skreślone wymagania występujące w poprzedniej wersji normy EN 287:1:2006: „Wymagania $h \leq t$ nie stosuje sie dla podtopienia. Podtopienie nie powinno przekraczać $0,5 \mathrm{~mm}$. Przesunięcie kątowe nie jest stosowane w przypadku egzaminu kwalifikacyjnego spawacza." 


\section{Wybrane zmiany w projekcie ISO/DIS 9606-1:2010}

\section{Procesy spawania}

111 spawanie łukowe elektrodą otuloną;

114 spawanie łukowe samoosłonowym drutem proszkowym;

121 spawanie łukiem krytym jednym drutem elektrodowym;

125 spawanie łukiem krytym drutem proszkowym;

131 spawanie elektrodą metalową w osłonie gazów obojętnych (spawanie MIG);

131-D spawanie metodą MIG, zwarciowe przechodzenie metalu;

131-G spawanie metodą MIG, kroplowe przechodzenie metalu;

131-S spawanie metodą MIG, natryskowe przechodzenie metalu;

135 spawanie elektrodą metalową w osłonie gazów aktywnych (spawanie MAG);

135-D spawanie metodą MAG, zwarciowe przechodzenie metalu;

135-G spawanie metodą MAG, kroplowe przechodzenie metalu;

135-S spawanie metoda MAG, natryskowe przechodzenie metalu;

136 spawanie łukowe $\mathrm{w}$ osłonie gazu aktywnego drutem proszkowym;

136-D spawanie drutem proszkowym w osłonie aktywnego gazu, zwarciowe przechodzenie metalu;

136-G spawanie drutem proszkowym w osłonie aktywnego gazu, kroplowe przechodzenie metalu;

136-S spawanie drutem proszkowym w osłonie aktywnego gazu, natryskowe przechodzenie metalu;

138-D spawanie drutem proszkowym o rdzeniu metalicznym, zwarciowe przechodzenie metalu;

138-G spawanie drutem proszkowym o rdzeniu metalicznym, kroplowe przechodzenie metalu;

138-S spawanie drutem proszkowym o rdzeniu metalicznym, natryskowe przechodzenie metalu;

141 spawanie elektrodą wolframową w osłonie gazów obojętnych (spawanie TIG);

142 spawanie elektrodą wolframową w osłonie gazu obojętnego bez dodatku spoiwa;

143 spawanie elektrodą wolframową w osłonie gazu obojętnego $z$ dodatkiem drutu lub pręta proszkowego;

145 spawanie elektrodą wolframową w osłonie gazu obojętnego z udziałem gazów redukujących i dodatkiem litego drutu lub pręta;

15 spawanie plazmowe;

311 spawanie acetylenowo - tlenowe.

Jeśli spawacz zdaje egzamin ze zwarciowego przechodzenia metalu (metody 131, 135 i 138), to ocena obejmuje również inne metody przechodzenia metalu przez łuk, lecz nie odwrotnie.
Tablica II. Materiały dodatkowe do spawania [1]

Table II. The filler metal grouping system [1]

\begin{tabular}{|l|l|l|}
\hline Grupa & $\begin{array}{l}\text { Materiał dodatkowy } \\
\text { do spawania }\end{array}$ & \multicolumn{1}{|c|}{ Stosowanye normy } \\
\hline FM1 & $\begin{array}{l}\text { stale niestopowe } \\
\text { i drobnoziarniste }\end{array}$ & $\begin{array}{l}\text { ISO 2560, ISO 14341, ISO 636, } \\
\text { ISO 14171, ISO 17632 }\end{array}$ \\
\hline FM2 & $\begin{array}{l}\text { stale o wysokiej } \\
\text { wytrzymałości }\end{array}$ & $\begin{array}{l}\text { ISO 18275, ISO 16834, ISO 26304, } \\
\text { ISO 18276 }\end{array}$ \\
\hline FM3 & $\begin{array}{l}\text { stale odporne na } \\
\text { pełzanie Cr }<3,75 \%\end{array}$ & $\begin{array}{l}\text { ISO 3580, ISO 21952, ISO 24598, } \\
\text { ISO 17634 }\end{array}$ \\
\hline FM4 & $\begin{array}{l}\text { stale odporne } \\
\text { na pełzanie } \\
3,75 \leq \text { Cr } \leq 12 \%\end{array}$ & $\begin{array}{l}\text { ISO 3580, ISO 21952, ISO 24598, } \\
\text { ISO 17634 }\end{array}$ \\
\hline FM5 & $\begin{array}{l}\text { stale nierdzewne } \\
\text { i żaroodporne }\end{array}$ & ISO 3581, ISO 14343, ISO 17633 \\
\hline FM6 & nikiel i stopy niklu & ISO 14172, ISO 18274 \\
\hline
\end{tabular}

Tablica III. Zakres kwalifikacji materiałów dodatkowych do spawania [1]

Table. III. The range of qualifications for welding with different filler metal [1]

\begin{tabular}{|c|c|c|c|c|c|c|}
\hline \multirow{2}{*}{$\begin{array}{l}\text { Spoiwo stosowane } \\
\text { podczas egzaminu }\end{array}$} & \multicolumn{6}{|c|}{ Zakres kwalifikacji } \\
\hline & FM1 & FM2 & FM3 & FM4 & FM5 & FM6 \\
\hline FM1 & $x$ & $x$ & - & - & - & - \\
\hline FM2 & $x$ & $\mathrm{X}$ & - & - & - & - \\
\hline FM3 & $x$ & $x$ & $x$ & - & - & - \\
\hline FM4 & $x$ & $x$ & $x$ & $x$ & - & - \\
\hline FM5 & - & - & - & - & $x$ & - \\
\hline FM6 & - & - & - & - & $x$ & $x$ \\
\hline \multicolumn{7}{|c|}{$\begin{array}{l}\text { Opis } \\
\text { x - wskazuje materiały dodatkowe, do spawania którymi spawacz } \\
\text { musi zdobyć uprawnienia. } \\
\text { - - wskazuje te materiały dodatkowe, do spawania którymi spawacz } \\
\text { nie jest kwalifikowany. } \\
\text { FM1 - stale niestopowe i drobnoziarniste; FM2 - stale o wysokie } \\
\text { wytrzymałości } \\
\text { FM3 - stale odporne na pełzanie } \mathrm{Cr}<3,75 \% \text {; } \\
\text { FM4 - stale odporne na pełzanie } 3,75 \leq \mathrm{Cr} \leq 12 \% \\
\text { FM5 - stale nierdzewne i żaroodporne; } \mathrm{FM}_{6}-\text { nikiel i jego stopy }\end{array}$} \\
\hline
\end{tabular}

W normie nie podano jednak granicznych parametrów prądowych (natężenie prądu spawania, napięcie łuku) w celu rozgraniczenia obszarów przechodzenia metalu. Komplikuje to egzamin spawacza, gdyż bez dodatkowego oprzyrządowania na egzaminie niejednokrotnie trudno będzie określić sposób przejścia metalu elektrody.

\section{Materiały dodatkowe do spawania}

Norma wprowadza zasadniczą zmianę w stosunku do obecnego systemu oceny uprawnień spawaczy. W normach europejskich i międzynarodowych zakres kwalifikowania przyporządkowano materiałowi 
podstawowemu, stosowanemu do wykonania złącza egzaminacyjnego. Nowa norma ISO/DIS 96061:2010 za podstawę zakresu kwalifikacji przyjmuje materiał dodatkowy zastosowany do spawania złącza egzaminacyjnego. Wprowadza także nowy system doboru materiałów dodatkowych do spawania, ujęty w tablicy II.

W materiałach dodatkowych dla elektrod otulonych wprowadzono też dodatkowe oznaczenia powiązane z PN-EN ISO 2560 (wg wytrzymałości na rozciąganie):

03 otulina rutylowo-zasadowa

10 otulina celulozowa

11 otulina celulozowa
12 otulina rutylowa

13 otulina rutylowa

14 otulina rutylowa z proszkiem żelaza

15 otulina zasadowa

16 otulina zasadowa

18 otulina zasadowa z proszkiem żelaza

19 otulina ilmenitowa

20 otulina z tlenku żelaza

24 otulina rutylowa z proszkiem żelaza

27 otulina z tlenku żelaza i proszkiem żelaza

28 otulina zasadowa z proszkiem żelaza

45 otulina zasadowa

48 otulina zasadowa

\section{Podsumowanie}

Przedstawione w artykule zmiany zasad egzaminowania spawaczy w nowej normie PN-EN 287--1:2011 i w projekcie normy międzynarodowej ISO/DIS 9606-1:2010 sygnalizują tylko najistotniejsze nowości. Obecnie obowiązuje norma PN-EN 287-1, ale wkrótce zostanie ona wycofana, stąd też warto już teraz przygotować się do zmian wynikających z normy 9601-1. Do najważniejszych zmian w normie międzynarodowej należy zaliczyć:

- ocenę charakteru przejścia metalu przez łuk spawalniczy;
- wprowadzenie nowego systemu doboru materiałów dodatkowych, będącego podstawą zakresu kwalifikacji (zamiast dotychczasowego sposobu wynikającego z materiału podstawowego);

- ocenę uprawnień w zależności od temperatury wstępnego podgrzania złączy egzaminacyjnych.

\section{Literatura}

[1] Kurpisz B.: Zmiany zasad egzaminowania spawaczy stali w nowej normie PN-EN 287-1: 2011 i projekcie normy międzynarodowej ISO/DIS 9606-1:2010. Materiały szkoleniowe.

[3] PN-EN 287-1:2011: Egzamin kwalifikacyjny spawaczy. Spawanie. Część 1: Stale. Instytut Spawalnictwa. Gliwice 2011.

[2] Pakos R.: Kwalifikowanie spawaczy stali w oparciu o wymagania norm europejskich i międzynarodowych. Przegląd Spawalnictwa $\mathrm{Nr} 6 / 2007$.

\section{SpawnLيICTü \\ www.pspaw.ps.pl}

